The following pages constitute the final, accepted and revised manuscript of the article:

Nilsson, Hans-Olof and Pietroiusti, Antonio and Gabrielli, Maurizio and Zocco,

Maria Assunta and Gasbarrini, Giovanni and Gasbarrini, Antonio

"Helicobacter pylori and Extragastric Diseases - Other Helicobacters"

Helicobacter. 2005;10 Suppl 1:54-65.

Publisher: Blackwell

Use of alternative location to go to the published version of the article requires journal subscription.

Alternative location: http://dx.doi.org/10.1111/j.1523-5378.2005.00334.x 


\section{HELICOBACTER PYLORI AND EXTRAGASTRIC DISEASES - OTHER HELICOBACTERS}

Hans-Olof Nilsson, Antonio Pietroiusti*, Maurizio Gabrielli\#, Maria Assunta Zocco\#, Giovanni Gasbarrini\#, Antonio Gasbarrini\#

Department of Laboratory Medicine, Lund University, Lund, Sweden

*Medical Semiology and Methodology, Department of Internal Medicine, Tor Vergata University, Rome, Italy

\#Department of Internal Medicine, Catholic University the Sacred Heart, Gemelli Hospital Rome, Italy

Correspondence and reprints request to:

Antonio Gasbarrini, MD

Istituto di Patologia Speciale Medica

Universita' Cattolica del Sacro Cuore

Policlinico Gemelli, Largo Gemelli 8,

00168 Rome, ITALY

Telephone: $\quad 39-335-6873562 \quad 39-6-30154294$

FAX: $\quad 39-6-35502775$

E-mail: $\quad$ angiologia@rm.unicatt.it 


\section{ABSTRACT}

The involvement of Helicobacter pylori in the pathogenesis of extragastric diseases continues to be an interesting topic in the field of Helicobacter-related pathology.

Although conflicting findings have been reported for most of the disorders, a role of $H$. pylori seems to be important especially for the development of cardiovascular and hematologic disorders. Previously isolated human and animal Helicobacter sp. flexispira and 'Helicobacter heilmannii' strains have been validated using polyphasic taxonomy. A novel enterohepatic helicobacter has been isolated from mastomys and mice, adding to the list of helicobacters that colonize the liver. Genetic targets that may aid the classification of novel Helicobacter species have emerged. Animal models of helicobacter-induced gastric- and hepatobiliary diseases have gained insights of mechanisms associated with premalignant transformation 


\section{EXTRAGASTRIC DISEASES}

Helicobacter pylori $(H$. pylori) infection, although confined to the stomach, induces a strong systemic immune host response. It is therefore plausible that untoward effects of this response may contribute to the development of disease in districts other than the gastrointestinal tract. Unfortunately, demonstration of a causal relationship is rather difficult, since the etiology of most of the disorders in which the organism might be involved is multifactorial, $H$. pylori being, at the best, one of the causative agents; furthermore, the organism is not directly involved, and results of eradication therapy are of difficult interpretation. With these limitations in mind, there are two main fields in which $H$. pylori probably play a role, at least in a subset of patients: clinical manifestations of atherosclerosis, and chronic idiopathic thrombocytopenic purpura. Association with other disorder is much less consistent.

\section{Clinical manifestations of atherosclerosis}

Published studies involve several aspects of the relationship between $H$. pylori infection and this disorder: epidemiologic association; pathophysiologic mechanisms; results of eradication therapy. Two case-control studies $(1,2)$ assessing the possible relationship between ischemic stroke and $H$. pylori gave discordant results (however, a significant association with CagA positive strains was detected in the negative report), whereas another study, assessing whether the natural history of infected patients with atherosclerotic stroke differs from that of uninfected ones, was unable to detect differences between infected and non infected patients: once again, a significant association with CagA positive strains was found in this study (3).

Two reports, by McDonald et al (4), and by Shmuely et al (5), focused on the possible relationship between Helicobacter pylori and atherosclerotic changes detectable at ultrasonography: both studies did not find an association; Shmuely et al, however, detected an increased risk for patients with CagA positive strains (this association was not examined in the other study). 
Some studies (6-9) examined the possibility that genomic material of $H$. pylori may be present in the context of atherosclerotic plaques: both positive $(6,7)$ and negative $(8,9)$ findings have been reported. It should be kept in mind that techniques of genoma amplification carry a high risk of both false positive and false negative findings.

As far as the possible relationship between infection and coronary artery disease (CAD), two casecontrol studies $(10,11)$ showed a higher prevalence of infection, whereas no significant difference was found in other reports (12-14). In a large cross-sectional survey (15), an association limited to diabetics was found. Of note, only one of the above reported studies (10) analysed CagA status, showing a significant association with active infection in CAD patients.

Three further studies focused on selected groups: diabetic patients(16), patients with end stage renal failure (17), and young patients (18), failing to detect an association.

An inverse correlation with the occurrence of venous by-pass graft occlusion after coronary artery by-pass surgery has been reported (19): caution is needed in the interpretation of this finding, due to the low number of studied patients and the very high rate of infection in patients without occlusion $(82 \%)$

One report examined the effects of eradication therapy on relapses in $H$. pylori positive CAD patients (20): a significant beneficial effect of therapy was reported.

Finally, possible pathophysiologic alterations linking $H$. pylori to cardiovascular disease have been explored in several studies: positive association of the infection with systemic markers of inflammation and/or with platelet or clotting factor activation or serum lipids has been reported $(11,21-23)$; the same parameters, however, were not found to be significantly associated in the majority of reports $(5,13,15-17,18,20,24)$. Interestingly, some negative reports found a positive association of infection with cardiovascular disease. This fact suggests that $H$. pylori may lead to overt atherosclerosis through other mechanisms. 
In conclusion, conflicting findings have been reported for a causal role of $H$. pylori in cardiovascular disease. By contrast, uniform positive findings have been obtained in studies taking into account the possible association with CagA positive strains.

\section{Idiopathic thrombocytopenic purpura (ITP) and other hematologic disorders}

Although most studies concerning this possible association failed to detect significant differences in the prevalence of infection between patients with or without this haematological disorder, there is little doubt that the administration of eradication therapy to H. pylori infected patients causes longlasting remission in approximately half of them. In published studies, the frequency of remission after treatment ranges from $45 \%$ to $74 \%$ (25-35). Although treatment seems more efficacious in older subjects, remissions are well documented also in children (36). Indirect evidence for a role of H. pylori infection in regulating platelet count, derives from a report showing the development of thrombocythemia after eradication (37). Interestingly, H. pylori has been implicated in other piastrininopenic states such as thrombotic thrombocytopenic purpura in patients after bone marrow transplantation (38). There is no established mechanism to explain how this organism, which does not invade the gastric mucosa, could be implicated in the pathogenesis of this immune-based platelet disorder. Several theories including molecular mimicry, platelet aggregation, and immunomodulatory effects of macrolides have been proposed to explain the platelet response to anti-H. pylori therapy. Large randomized-controlled studies enrolling patients from various ethnic backgrounds will be necessary to determine the response rate and mechanism of response and to gain a better understanding of the pathogenesis of ITP (39).

H. pylori infection has ben implicated in other hematologic disorders, such as sideropenic and megaloblastic anemia. The organism may theoretically cause host iron deficiency by directly competing with the host for available iron or by impairing iron uptake as a consequence of atrophyassociated gastric hypochlorhydria. This hypothesis has been confirmed by a study showing an impaired absorption of iron after oral load in infected subjects, and reversion to normal after 
eradication (40). The relevance of this effect is probably marginal, however, and may have a clinical expression in the case of limited iron stores associated with reduced iron intake, as shown in animals (41). Indeed, in some situations at risk for iron deficiency anemia, such as pregnancy (42), subtotal gastrectomy (43) and celiac disease (44), an association with infection has been suggested. Results of eradication therapy are not uniform: whereas it was found ineffective in Bangladeshi children with iron deficiency anemia (45), impressive benefits have been claimed in some casereports $(46,47)$. These conflicting findings may be explained by genetic polymorphism of the organism, which may render some strains more prone to metabolize iron (48)

The mechanism by which $H$. pylori may lead to vitamin B12 deficiency, imply the presence of corpus atrophich gastritis (which is not the most frequent event related to H. pylori infection), and consequent low secretion of intrinsic factor necessary for cobalamin absorption. Once again, the organism may have clinical relevance in extreme clinical situations, such as hemodialysis patients (49); on the other hand, Van Oijen et al. failed to detect a contribution of the organism in other vitamin B12 associated states, such as alcoholism (50). Two studies recently reported an association of Chronic NSAIDS use and urticaria with cobalamin deficiency: both studies did not detect a role of $H$. pylori in determining this situation $(51,52)$. A case report claimed persistent remission of megaloblastic anemia after $H$. pylori eradication (53).

\section{Immunologic and allergic disorders}

An immuno-mediated mechanism has been considered in many potentially $H$. pylori related disorders such as cardiovascular disease and idiopathic thrombocytopenic purpura. On this basis, studies have been performed on a possible role of the organism in classic immunologic and allergic disorders.

Two studies, evaluating opposite hypotheses, have been tested on a general role of $H$. pylori in allergy: the first one, based on the well known negative association between the presence of orofecally transmitted organisms and allergy, searched for a protective role of the organism in allergic 
diathesis; the second one, based on the capability of $H$. pylori to increase gastric permeability, examined the possible predisposition to food allergy in infected subjects. Both studies $(54,55)$ gave negative findings.

As far as the association with specific disorders is concerned, no association has been found in case-control studies concerning primary biliary cirrhosis (56), and rosacea (57). For the latter, the possibility of an association with specific histologic subtypes has been suggested (58).

A report based on response to eradication therapy (59) has suggested an association of $H$. pylori infection with thyroid autoantibodies, whereas a cross-sectional survey, including consecutive dyspeptic patients undergoing upper GI endoscopy, did not detect an increase in the prevalence of these autoantibodies (60). However, infection may be involved in specific autoimmune disorders such as Hashimoto thyroiditis (61), as suggested by Franceschi et al.

In a cross-sectional survey, Rybar et al. (62) observed that, among patients with rheumatoid arthritis, those with both IgG and IgA antibodies against $H$. pylori had a higher propensity to have involvement of sites other than joints. Altered intestinal permeability, induced by the organism, may explain the association with this disorder, as well as with other rheumatologic conditions, such as seronegative spondyloarthritis (63), and Sjogren's syndrome (64).

The mechanism underlying the possible association of urticaria with $H$. pylori remains still elusive. In fact, impressive benefit after eradication therapy has been reported $(65,66)$. Furthermore, in one of the two above reported studies, no remission was observed in patients in whom antibiotic therapy failed to eradicate the organism (66). On the other hand, the same study did not show any difference in the rate of infection between patients and controls, and the proposed mechanism of $H$. pylori linked altered gastrointestinal permeability has not been demonstrated in infected patients with food related urticaria (67). It is possible that a IgA- and IgE-mediated immune response against antioxidative bacterial proteins may arise in some infected subjects, inducing this skin disorder (68). One case-control study in patients with nasal polyps did not detect differences in the prevalence of 
infection between patients and controls (69); the organism was however identified by immunohistochemistry in 6 specimens taken from polyps.

\section{Miscellaneous}

Among neurological disorders, Malaguarnera et al found significantly higher IgG levels against $H$. pylori in patients with Alzheimer disease than in controls (70). Similar findings have been reported in a case control study of patients with Guillain-Barrè syndrome (71): it is ironic that the controls of this study were represented by patients with iron deficiency anemia, a condition which might be related to $H$. pylori infection. A relationship with migraine has been suggested by Tunca et al (72), showing that the eradication of the bacterium can reduce frequency, duration and severity of clinical attacks of the disease. Finally, an impaired autonomic nervous function has been shown in infected patients with atypical chest pain by Budzynski et al (73)

Some interest has recently been generated on possible consequences of infection on body mass index.. Indeed infection may decrease serum ghrelin and increase gastric leptin levels, which may, in turn, decrease body mass index. On this basis, some studies have focused on these possible hormonal changes, whereas other reports pointed out to the clinical counterpart of these alterations. Ioannou et al.(74) measured serum leptin levels and body mass index in 6724 adult subjects: he was unable to find any relationship of these variables with the presence of infection. Similarly, Nishi et al. did not detect increased levels of serum leptin in infected patients, although they found an increased expression at the level of gastric mucosa (75) By contrast, relevant changes in gastric ghrelin expression (76), and in plasma ghrelin concentration (77) have been reported by Japanese authors after eradication therapy; furthermore, an increase of body mass index (78) has been reported in peptic ulcer patients one year after. It is possible that these non uniform findings may reflect the fact that substantial alterations in the levels of ghrelin may be observed only when infection induces gastric atrophy (79). 
A possible causative role of $H$. pylori in upper respiratory infections and otitis media has been tested by Pitkaranta et al (80): they failed, however, to detect the organism from culture of samples of adenoid tissue and middle ear fluid. In the context of respiratory pathology, an increased seroprevalence of $H$. pylori infection and especially of CagA positive strains, has been reported in a case-control study concerning 126 patients with chronic obstructive pulmonary disease (COPD), and 126 controls (81): a possible confounding role of concomitant cardiovascular disease cannot however be excluded. In another case-control study, no difference in the prevalence of infection was found between COPD patients and controls (82).

Response to eradication therapy has been examined in type 1 diabetes by Candelli et al. (83): they found a similar rate of eradication in subjects with the disease and in dyspeptic controls; furthermore, no improvement in glycemic control was observed in treated patients. An inverse association between infection and end stage renal failure has been reported in type 2 diabetic patients with renal insufficiency (84). However, this somewhat surprising finding was based on a small number of patients and should be confirmed by further larger series.

Hormonal changes, consisting in increased levels of circulating insulin like growth factor and cortisol have been reported (85); pathophysiologic premises for these alterations remain unclear, however.

As far as oral diseases are concerned, the possible involvement of $H$. pylori in teeth loss has ben tested by Peerce et al (86), who found a relationship between teeth loss and infection examining 334 individuals aging 50 years. The correlation was no longer detectable after multivariate analysis taking into account socio-economic status. A beneficial effect of eradication therapy in recurrent aphthous stomatitis has also been reported (87)

A possible correlation with ocular disorders has also been assessed: an increased prevalence of $H$. pylori infection in patients with central serous chorioretinopathy and diffuse retinal epitheliopathy, as compared with historical controls has been reported (88), whereas no relationship between infection and age related neovascular macular degeneration was found (89). 
As far as the correlation with neoplasia is concerned, Nurgalieva et al (90), in an elegant casecontrol study, suggested a possible marginal role of $\mathrm{H}$. pylori infection in laryngeal cancers not associated with HPV-16 infection; in another study, search for the organism by himmunohistochenical methods in normal and neoplastic laryngeal tissue yelded negative findings (91). Finally, on the basis of the findings of a case-control study, Philipou et al (92) denied a possible involvement of the organism in lung cancer.

An experimental study in mouse has shown an adverse outcome of pregnancy (higher numbers of resorption and lower fetal weights) in infected animals (93). These findings need to be confirmed in humans for assessing their clinical relevance.

There is some suggestion, based on detection of bacterial DNA (94), that H. pylori may be present in gallbladders harbouring cholesterol gallstones. It remains unclear, however, whether this organism is an innocent bystander or active participant in gallstone formation.

In hepatology, Helicobacter 16S rDNA (from H. pylori- and H. pullorum-like organisms) was found in only $4.2 \%$ of liver samples from controls and in $3.5 \%$ from patients with non-cirrothic chronic hepatitis $\mathrm{C}$ with respect to $68 \%$ of liver samples from patients with HCV positive cirrhosis without hepatocellular carcinoma and $61.3 \%$ from from patients with $\mathrm{HCV}$ positive cirrhosis with hepatocellular carcinoma (95). Another recent study found Helicobacter 16S rDNA to be present in 8 of 20 samples of primary liver carcinoma (6 showing high similarity to DNA of $H$. pylori) with respect to none in the control group (96). Results from these retrospective studies warrants prospective trials to determine the possible causal role of these bacteria in the progression of chronic hepatitis $\mathrm{C}$ and in hepatocarcinogenesis.

The suggestion that ammonia production due to bacterial urea breakdown may contribute to hepatic encephalopathy in patients with liver failure comes from a study showing an association between infection and the degree of porto-systemic encephalopathy (97). 


\section{OTHER HELICOBACTERS}

\section{Identification and classification}

Human, primate and pig isolates of the large tightly coiled bacterium 'Helicobacter heilmannii' have been characterized by phylogenetic analysis (98). Fifteen isolates clustered with 'Candidatus Helicobacter suis', whereas 11 strains could not be differentiated from Helicobacter bizzozeronii, Helicobacter felis and Helicobacter salomonis. Urease gene analysis separated these isolates into the above three and a fourth distinct cluster containing human and feline isolates. This cluster of isolates was proposed as a unique species with the provisional name 'Candidatus Helicobacter heilmannii' (98).

Helicobacter mastomyrinus was isolated from the liver and cecum of mastomys and from cecum and feces of normal mice (99). Based on $16 \mathrm{~S}$ rDNA and phenotypic traits, the bacterium was closely related to 'Helicobacter muricola' and expressed urease, cytolethal distending toxin and caused cell distention. Livers of mastomys from which this novel helicobacter was isolated showed mild inflammation around bile ducts and focal hepatitis with necrosis (99).

$16 \mathrm{~S}$ rDNA analysis may not differentiate helicobacters to the species level and does not necessarily correspond to results of polyphasic taxonomy. Gene analysis of the $60 \mathrm{kDa}$ heat-shock protein (HSP60) demonstrated a higher resolution than conventional 16S rDNA for species identification of gastric and enterohepatic Helicobacter spp. $(98,100)$.

Characterization of 16S rRNA, ureaseB, and HSP60 gene sequences, DNA-DNA hybridization, as well as phenotypic analysis of Finnish canine and feline isolates as well as reference strains of Helicobacter sp. flexispira taxa 2, 3 and 8, demonstrated that these strains are members of the species Helicobacter bilis (101).

\section{Diagnosis}


A duplex PCR for routine analysis of Helicobacter species in murine feces utilized intestinal Lactobacillus species as an internal standard, demonstrating the usefulness of a quality control, extendable to other feces tests, to rule out false negative PCR results (102).

Novel gene targets for five common murine helicobacters, H. bilis, Helicobacter hepaticus, Helicobacter muridarum, Helicobacter rodentium, and Helicobacter typhlonius, have been used to construct a multiplex PCR-assay, allowing species-level detection of some common rodent species without subsequent restriction fragment analysis (RFLP) or DNA-sequencing (103). A recombinant immunoreactive protein (P167) of $\mathrm{H}$. bilis, coupled to microbeads in a multiplex assay format, demonstrated sensitive and specific serodetection of $H$. bilis with high-throughput and low batch-tobatch variation (104).

Visualization of Helicobacter spp. using $16 \mathrm{~S}$ rDNA probes, for Helicobacteraceae or specifically for H. hepaticus or Helicobacter ganmani, and fluorescent in situ hybridization (FISH), demonstrated spatial differences in helicobacter colonization of the mouse cecum (105).

\section{Pathogenesis}

Few candidate virulence factors of non-pylori Helicobacter spp. have been identified; however, the H. hepaticus cytolethal distending toxin (CDT), also expressed by some other enterohepatic Helicobacter species (EHS), was shown to mediate a previously described cytopathic effect on cultured cells. Isogenic $H$. hepaticus CDT-negative mutants colonized mice but with a markedly attenuated capacity to induce lesions in a murine IBD model (106).

Analysis of the lipopolysaccharide (LPS) of gastric and enterohepatic Helicobacter species demonstrated some structural heterogeneity in LPS-moieties and that LPSs of some EHS induced significantly lower Limulus amoebocyte lysate activity compared with Helicobacter pylori, nonetheless, the LPS of all analyzed species induced NF-kB activation in cultured cells (107).

Moreover, helicobacter LPS induced cytokine signaling mediated by Toll-like receptor (TLR) 4, whereas the cytokine response to intact gastric (H. pylori, H. felis) or EHS (H. hepaticus) was 
mediated by TLR2, features that were observed using macrophages and monocytes as well as in mice with various TLR-deficiencies (108).

\section{Animal models and natural infection}

H. felis causes a persistent chronic inflammation that with time progresses to gastric cancer in some strains of mice, an established model of $H$. pylori-induced gastric disease in humans. Transgenic mice overexpressing amidated as well as glycine-extended gastrin were inoculated with $H$. felis and long-term effects included increased susceptibility to ulcer disease whereas $H$. felis-mediated preneoplastic progression was delayed (109).

In H. felis infected C57-mice oxyntic atrophy of the fundus is associated with a spasmolytic polypeptide expressing metaplastic (SPEM) cell lineage. Novel studies in this animal model described SPEM-related gene transcripts associated with gastritis cystica profunda and suggested that SPEM represents a precursor lineage of dysplasia in this animal model of gastric carcinogenesis (110).

BALB/c-mice do not develop clinical disease with either of the organisms $H$. felis or Toxoplasma gondii. However, long-term coinfection induced severe disease, including gastric atrophy and metaplastic changes, and increased mortality rates by modulating the host immune response towards a Th1 dominated phenotype (111).

'H. heilmannii' is prevalent in many animal species and causes gastric disease in a small percentage of patients. Specific pathogen-free mice inoculated with human and animal isolates of 'H. heilmannii' developed gastric mucosa associated lymphoid tissue (MALT) lymphoma. More severe pathology was observed in animals infected with 'H. heilmannii' as opposed to $H$. felis or $H$. pylori (112).

H. hepaticus induces chronic hepatitis that progresses to hepatocellular carcinoma in the $\mathrm{A} / \mathrm{JCr}$ mouse. Studies of the pathogenesis of premalignant disease in this model revealed that early infection (first weeks of life) leads to disease development and that male mice are more susceptible 
to infection (113). In this model of infectious liver cancer, hepatic gene expression profiles, monitored during one year of $H$. hepaticus infection, identified putative tumor markers that correlated with advancing hepatocellular dysplasia (114).

The influence of some EHS on cholesterol gallstone formation in susceptible $\mathrm{C} 57 \mathrm{~L} / \mathrm{J}$ mice showed that cholesterol cholelithogenesis significantly accelerated in mice infected with $H$. bilis or dual-infected with $H$. hepaticus and Helicobacter rodentium (115).

$H$. rodentium has not been implicated in cecal or hepatic lesion formation in SCID or $\mathrm{A} / \mathrm{JCr}$ mice, however, immunodeficient mice co-infected with $H$. hepaticus and $H$. rodentium displayed augmented disease compared with $H$. hepaticus infection alone (116).

Male A/JCr mice seem more susceptible to develop helicobacter-induced hepatic disease. However, in the same strain of mice chronically infected with $H$. hepaticus, female mice developed more severe intestinal inflammation than did infected male mice (117).

Murine-derived probiotic lactobacilli have been shown to reduce $H$. hepaticus-induced colitis in interleukin (IL) 10 deficient mice by modulation of the mucosal (TNF- $\alpha$ and IL-12) inflammatory response (118).

$H$. bilis caused mild to severe chronic inflammation of the liver of outbred Swiss mice and seroconversion to $H$. bilis outer membrane antigens was common in 6- to 8-month-old mice with hepatitis (119).

A systematic investigation of laboratory rodents demonstrated a high prevalence of Helicobacter species in several academic animal facilities. An endemic colonization pattern was observed and up to five Helicobacter species, identified by PCR denaturing gradient electrophoresis and sequencing were found in a single facility (120).

Chinese wild rodents, such as gerbils, jerboas and rats, are hosts for the common rodent species H. hepaticus and H. ganmani, as well as Helicobacter winghamensis and Helicobacter canadensis (121). The latter two species have been isolated from diarrheic humans. 
Seven of 23 examined captive rabbits were positive for spiral gastric bacteria related to $H$. felis, H. salomonis, and a putative novel species by $16 \mathrm{~S}$ rDNA analysis (122).

A high prevalence $(>90 \%)$ of 'Candidatus Helicobacter suis' was detected in pig stomach mucosa and gastric inflammation was common (>60\%) among positive animals (123).

Spiral gastric bacteria in the stomach of cheetahs were similar to 'Helicobacter heilmannii' by morphology and 16S rDNA analysis. Helicobacter-infected captive cheetahs displayed gastritis whereas wild cheetahs did not. Host factors likely account for disease development in the captive animals (124).

Possibly novel Helicobacter and Wolinella spp., related to helicobacters previously isolated in seals, otters and dolphins, and to Wolinella succinogenes, respectively, have been identified in sea lions with gastritis and ulceration (125). 


\section{REFERENCES:}

1. Preusch M R, Grau A J, Buggle F, et al. Association Between Cerebral Ischemia and Cytotoxin-Associated Gene-A-Bearing Strains of Helicobacter pylori. Stroke 2004;35:1800-1804.

2. Sawayama Y, Ariyama I, Hamada M, et al. Association between chronic Helicobacter pylori infection and acute ischemic stroke: Fukuoka Harasanshin Atherosclerosis Trial (FHAT). Atherosclerosis. 2005; 178:303-9.

3. Diomedi M, Pietroiusti A, Silvestrini M, et al. CagA-positive Helicobacter pylori strains may influence the natural history of atherosclerotic stroke. Neurology. 2004;63:800-4.

4. Mc Donald S, Maguire GM, Duarte N, Li Wang X, Hoy WE. Carotid intima-media tickness, cardiovascular risk factors and albuminuria in a remote Australian aboriginal community. Atherosclerosis 2004; 177: 423-31.

5. Shmuely H, Passaro DJ, Vaturi M et al. Association of $\mathrm{CagA}^{+}$Helicobacter pylori with aortic atheroma. Atherosclerosis 2005; 179: 127-32.

6. Latsios G, Saetta A, Michalopoulos NV, Agapitos E, Patsouris E. Detection of cytomegalovirus, Helicobacter pylori and Chlamydia pneumoniae DNA in carotid atherosclerotic plaques by the polymerase chain reaction. Acta Cardiol. 2004;59:652-7.

7. Pinar A, Oc M, Akyon Y, et al. Investigation of the presence of Chlamydophila pneumoniae, Helicobacter pylori and cytomegalovirus in human atherosclerosis by molecular and serological methods Mikrobiyol Bul. 2004;38:213-22.

8. Skowasch D, Jabs A, Andrie R, et al. Pathogen burden, inflammation, proliferation and apoptosis in human in-stent restenosis. Tissue characteristics compared to primary atherosclerosis. J Vasc Res. 2004;41:525-34.

9. Sulewska A, Modrzejewski W, Kovalchuk O, et al. Attempts to detect Helicobacter pylori in atherosclerotic plaques. Rocz Akad Med Bialymst. 2004;49 Suppl 1:239-41 
10. Aceti A, Are R, Sabino G, et al. Helicobacter pylori active infection in patients with acute coronary heart disease. J Infect. 2004;49:8-12.

11. Andreica V, Sandica-Andreica B, Draghici A, Chiorean E, Georoceanu A, Rusu M. The prevalence of anti-Helicobacter pylori antibodies in the patients with ischemic heart disease. Rom J Intern Med. 2004;42:183-9.

12. Sheehan J, Kearney PM, Sullivan SO, Mongan C, Kelly E, Perry IJ. Acute coronary syndrome and chronic infection in the Cork coronary care case-control study. Heart. 2005;91:19-22.

13. Lee SY, Kim DK, Son HJ, et al. The impact of Helicobacter pylori infection on coronary heart disease in a Korean population. Korean J Gastroenterol. 2004;44:193-8.

14. Lanza GA, Sestito A, Cammarota G, et al. Assessment of systemic inflammation and infective pathogen burden in patients with cardiac syndrome X. Am J Cardiol. 2004 ;94:404.

15. Gillum RF. Infection with Helicobacter pylori, coronary heart disease, cardiovascular risk factors, and systemic inflammation: the Third National Health and Nutrition Examination Survey. J Natl Med Assoc. 2004;96:1470-6.

16. Ongey M, Brenner H, Thefeld W, Rothenbacher D. Helicobacter pylori and hepatitis A virus infections and the cardiovascular risk profile in patients with diabetes mellitus: results of a population-based study. Eur J Cardiovasc Prev Rehabil. 2004;11:471-6.

17. Wolf SC, Brehm BR, Mayer O, Jurgens S, Schultze G, Risler T. Infectious risk factors for atherosclerotic vascular disease in hemodialysis patients--Chlamydia pneumoniae but not Helicobacter pylori or cytomegalovirus is associated with increased C-reactive protein. Ren Fail 2004;26:279-87.

18. Assanelli D, Bonanome A, Grassi M, et al. Determinants of early-onset cardiovascular disease: a case-control study of young myocardial infarction patients. Ital Heart J. 2004;8:604-11. 
19. Limnell V, Pasternack R, Karjalainen J, Virtanen V, Lehtimaki T, Aittoniemi J. Seropositivity for Helicobacter pylori antibodies is associated with lower occurrence of venous bypass graft occlusion. Scand J Infect Dis 2004;36:601-3.

20. Elizalde JI, Perez-Pujol S, Heras M, et al. Effects of Helicobacter pylori eradication on platelet activation and disease recurrence in patients with acute coronary syndromes. Helicobacter 2004; 9:681.

21. Davi G, Neri M, Falco A, et al. Helicobacter pylori infection causes persistent platelet activation in vivo through enhanced lipid peroxidation. Arterioscler Thromb Vasc Biol. $2005 ; 25: 246-51$.

22. Saribas S, Kocazeybek B, Aslan M, et al. Do procalcitonin and C-reactive protein levels have a place in the diagnosis and follow-up of Helicobacter pylori infections? J Med Microbiol. 2004;53:639-44.

23. Consolazio A, Borgia MC, Ferro D, et al. Increased thrombin generation and circulating levels of tumour necrosis factor-alpha in patients with chronic Helicobacter pylori-positive gastritis. Aliment Pharmacol Ther. 2004;20:289-94.

24. Kayo S, Ohsawa M, Ehara S, et al. Oxidized low-density lipoprotein levels circulating in plasma and deposited in the tissues: comparison between Helicobacter pylori-associated gastritis and acute myocardial infarction. Am Heart J. 2004;148:818-25.

25. Inaba T, Mizuno M, Take S, et al. Eradication of Helicobacter pylori increases platelet count in patients with idiopathic thrombocytopenic purpura in Japan. Eur J Clin Invest. 2005;35:214-9.

26. Ando T, Tsuzuki T, Mizuno T, et al. Characteristics of Helicobacter pylori-induced gastritis and the effect of $\mathrm{H}$. pylori eradication in patients with chronic idiopathic thrombocytopenic purpura. Helicobacter. 2004;9:443-52. 
27. Fujimura K, Kuwana M, Kurata Y, et al. Is eradication therapy useful as the first line of treatment in Helicobacter pylori-positive idiopathic thrombocytopenic purpura? Analysis of 207 eradicated chronic ITP cases in Japan. Int J Hematol. 2005;81:162-8.

28. Hashino S, Ota S, Kobayashi S, et al. Current status of treatment for patients with idiopathic thrombocytopenic purpura in the Hokkaido area (evaluation of Helicobacter pylori eradication). Rinsho Ketsueki. 2004;45:539-45.

29. Sato K, Nagai T, Muroi K, Komatsu N, Ozawa K. Helicobacter pylori eradication in patients with idiopathic thrombocytopenic purpura: the association between the activity of Helicobacter pylori and platelet recovery. Rinsho Ketsueki. 2004;45:1252-4.

30. Kurtoglu E, Kayacetin E, Ugur A. Helicobacter pylori infection in patients with autoimmune thrombocytopenic purpura. World J Gastroenterol. 2004;10:2113-5.

31. Sato R, Murakami K, Watanabe K, et al. Effect of Helicobacter pylori eradication on platelet recovery in patients with chronic idiopathic thrombocytopenic purpura. Arch Intern Med. 2004;164:1904-7.

32. Veneri D, Krampera M, Franchini M. Helicobacter pylori infection and idiopathic thrombocytopenic purpura: description of 21 newly diagnosed cases. Haematologica. 2004;89:ECR08.

33. Veneri D, Krampera M, Franchini M. High prevalence of sustained remission of idiopatic thrombocytopenic purpura after Helicobacter pylori eradication: a long-term follow-up study. Platelets 2005; 16: 117-9.

34. Matsusaki S, Wakita Y, Minamikawa K, Uemura Y, Nakashima K, Yamaguchi T. Platelet recovery of idiopathic thrombocytopenic purpura after eradication of Helicobacter pylori: report of two cases. Nippon Naika Gakkai Zasshi. 2004;93:771-3.

35. Asaumi N, Niiya K, Yoshida C, Shibakura M, Niiya M, Tanimoto M. Complete remission of cyclic thrombocytopenia after Helicobacter pylori eradication. Blood Coagul Fibrinolysis. 2004;15:439-40. 
36. Kurekci AE, Atay AA, Sarici SU, Ozcan O. Complete platelet recovery after treatment of Helicobacter pylori infection in a child with chronic immune thrombocytopenic purpura: a case report. Pediatr Hematol Oncol. 2004;21:593-6.

37. Veneri D, Franchini M. Onset of idiopathic thrombocythemia after Helicobacter pylori eradication. Helicobacter. 2005;10:95.

38. Takatsuka H, Wakae T, Toda A, et al. Association of Helicobacter pylori with thrombotic thrombocytopenic purpura and hemolytic uremic syndrome after bone marrow transplantation. Clin Transplant. 2004;18:547-51.

39. Jackson S, Beck PL, Pineo GF, Poon MC. Helicobacter pylori eradication: novel therapy for immune thrombocytopenic purpura? A review of the literature. Am J Hematol. 2005;78:142-50.

40. Ciacci C, Sabbatini F, Cavallaro R, et al. Helicobacter pylori impairs iron absorption in infected individuals. Dig Liver Dis. 2004;36:455-60.

41. Keenan JI, Peterson RA, Fraser R, et al. The effect of Helicobacter pylori infection and dietary iron deficiency on host iron homeostasis: a study in mice. Helicobacter. 2004; 9:64350.

42. Weyermann M, Rothenbacher D, Gayer L, et al. Role of Helicobacter pylori infection in iron deficiency during pregnancy. Am J Obstet Gynecol. 2005;192:548-53.

43. Roviello F, Fotia G, Marrelli D, De Stefano A, Macchiarelli R, Pinto E. Iron deficiency anemia after subtotal gastrectomy for gastric cancer. Hepatogastroenterology. 2004;5:15104.

44. Demir H, Saltik IN, Yuce A, Ozen H, Gurakan F, Kocak N. Is there any relation between Helicobacter pylori infection and iron deficiency anemia in children with celiac disease? Helicobacter. 2004;9:284.

45. Sarker SA, Davidsson L, Mahmud H, et al. Helicobacter pylori infection, iron absorption, and gastric acid secretion in Bangladeshi children. Am J Clin Nutr. 2004;80:149-53. 
46. Diop S, Aouba A, Varet B. Reversal of iron deficiency anaemia after eradication of Helicobacter pylori infection. Presse Med. 2004;33:1517-8.

47. Sakabe H, Yagi Y, Kakinoki R, Yoshikawa K, Inoue T, Fujiyama Y. Successful treatment of long-standing iron-deficiency anemia in adults by eradication of Helicobacter pylori. Rinsho Ketsueki. 2004;45:402-4.

48. Jeon BH, Oh YJ, Lee NG, Choe YH. Polymorphism of the Helicobacter pylori feoB gene in Korea: a possible relation with iron-deficiency anemia? Helicobacter. 2004;9:330-4.

49. Trimarchi H, Forrester M, Schropp J, Pereyra H, Freixas EA. Low initial vitamin B12 levels in Helicobacter pylori--positive patients on chronic hemodialysis. Nephron Clin Pract. 2004;96:28-32.

50. Van Oijen MG, Laheij RJ, de Jong CA, Peters WH, Jansen JB. Vitamin B12 status and its association with Helicobacter pylori infection in alcohol dependent patients. J Nutr Sci Vitaminol. 2004;50:305-8.

51. Van Oijen MG, Laheij RJ, Peters WH, Jansen JB, Verheugt FW; BACH study. Association of aspirin use with vitamin B12 deficiency (results of the BACH study). Am J Cardiol. 2004 Oct 1;94:975-7.

52. Mete N, Gulbahar O, Aydin A, Sin AZ, Kokuludag A, Sebik F. Low B2 levels in chronic idiopathic urticaria. J Investig Allergol Clin Immunol. 2004;14:292-9.

53. Kazimierska E, Podlaska M. Macrocytic megaloblastic anaemia in a patient with Helicobacter pylori infection. Pol Merkuriusz Lek. 2004;17:58-9.

54. Jarvis D, Luczynska C, Chinn S, Burney P. The association of hepatitis A and Helicobacter pylori with sensitization to common allergens, asthma and hay fever in a population of young British adults. Allergy. 2004;59:1063-7.

55. Kolho KL, Haapaniemi A, Haahtela T, Rautelin H. Helicobacter pylori and specific immunoglobulin E antibodies to food allergens in children. J Pediatr Gastroenterol Nutr 2005;40:180-3. 
56. Durazzo M, Rosina F, Premoli A, et al. Lack of association between seroprevalence of Helicobacter pylori infection and primary biliary cirrhosis. World J Gastroenterol. 2004;10:3179-81.

57. Baz K, Cimen MY, Kokturk A, et al. Plasma reactive oxygen species activity and antioxidant potential levels in rosacea patients: correlation with seropositivity to Helicobacter pylori. Int J Dermatol. 2004;43:494-7.

58. Aroni K, Tsagroni E, Lazaris AC, Patsouris E, Agapitos E. Rosacea: a clinicopathological approach. Dermatology. 2004;209:177-82.

59. Bertalot G, Montresor G, Tampieri M, et al. Decrease in thyroid autoantibodies after eradication of Helicobacter pylori infection. Clin Endocrinol 2004;61:650-2.

60. Tomasi PA, Dore MP, Fanciulli G, Sanciu F, Realdi G, Delitala G. Is there anything to the reported association between Helicobacter pylori infection and autoimmune thyroiditis? Dig Dis Sci. 2005;50:385-8.

61. Franceschi F, Satta MA, Mentella MC, et al. Helicobacter pylori infection in patients with Hashimoto's thyroiditis. Helicobacter 2004;9:369.

62. Rybar I, Rovensky J, Masaryk P, Mateicka F, Revayova I. Seroprevalence of Helicobacter pylori in rheumatoid arthritis and its relationship to pharmacotherapy. Vnitr Lek. 2004;50:911-6.

63. Di Leo V, D'Inca R, Bettini MB, et al. Effect of Helicobacter pylori and eradication therapy on gastrointestinal permeability. Implications for patients with seronegative spondyloarthritis. J Rheumatol. 2005 Feb;32(2):295-300.

64. El Miedany YM, Baddour M, Ahmed I, Fahmy H. Sjogren's syndrome: concomitant H. Pylori infection and possible correlation with clinical parameters. Joint Bone Spine. 2005;72:135-41.

65. Vazquez Romero M, Bermejo San Jose F, Boixeda de Miquel D, et al. Chronic urticaria and Helicobacter pylori. Med Clin (Barc). 2004;122:573-5. 
66. Fukuda S, Shimoyama T, Umegaki N, Mikami T, Nakano H, Munakata A. Effect of Helicobacter pylori eradication in the treatment of Japanese patients with chronic idiopathic urticaria. J Gastroenterol. 2004 ;39:827-30.

67. Buhner S, Reese I, Kuehl F, Lochs H, Zuberbier T. Pseudoallergic reactions in chronic urticaria are associated with altered gastroduodenal permeability. Allergy. 2004;59:1118-23.

68. Mini R, Figura N, D'Ambrosio C, et al. Helicobacter pylori immunoproteomes in case reports of rosacea and chronic urticaria. Proteomics. 2005;5:777-87.

69. Koc C, Arikan OK, Atasoy P, Aksoy A. Prevalence of Helicobacter pylori in patients with nasal polyps: a preliminary report. Laryngoscope. 2004;114:1941-4.

70. Malaguarnera M, Bella R, Alagona G, Ferri R, Carnemolla A, Pennisi G. Helicobacter pylori and Alzheimer's disease: a possible link. Eur J Intern Med. 2004;15:381-386.

71. Kountouras J, Deretzi G, Zavos C, et al. Association between Helicobacter pylori infection and acute inflammatory demyelinating polyradiculoneuropathy. Eur J Neurol. 2005;12:13943.

72. Tunca A, Turkay C, Tekin O, Kargili A, Erbayrak M. Is Helicobacter pylori infection a risk factor for migraine? A case-control study. Acta Neurol Belg. 2004;104:161-4.

73. Budzynski J, Klopocka M, Bujak R, Swiatkowski M, Pulkowski G, Sinkiewicz W. Autonomic nervous function in Helicobacter pylori-infected patients with atypical chest pain studied by analysis of heart rate variability. Eur J Gastroenterol Hepatol. 2004;16:451-7.

74. Ioannou GN, Weiss NS, Kearney DJ. Is Helicobacter pylori seropositivity related to body mass index in the United States? Aliment Pharmacol Ther. 2005;21:765-72.

75. Nishi Y, Isomoto H, Uotani S, et al. Enhanced production of leptin in gastric fundic mucosa with Helicobacter pylori infection. World J Gastroenterol. 2005;11:695-9.

76. Tatsuguchi A, Miyake K, Gudis K, et al. Effect of Helicobacter pylori infection on ghrelin expression in human gastric mucosa. Am J Gastroenterol. 2004;99:2121-7 
77. Osawa H, Nakazato M, Date $\mathrm{Y}$, et al. Impaired production of gastric ghrelin in chronic gastritis associated with Helicobacter pylori. J Clin Endocrinol Metab. 2005;90:10-6.

78. Kamada T, Hata J, Kusunoki H, et al. Eradication of Helicobacter pylori increases the incidence of hyperlipidaemia and obesity in peptic ulcer patients. Dig Liver Dis. $2005 ; 37: 39-43$.

79. Masaoka T, Suzuki H, Imaeda H, et al. Long-term strict monitoring of plasma ghrelin and other serological markers of gastric diseases after Helicobacter pylori eradication. Hepatogastroenterology. 2005;52:1-4.

80. Pitkaranta A, Kolho KL, Rautelin H. Helicobacter pylori in children who are prone to upper respiratory tract infections. Arch Otolaryngol Head Neck Surg. 2005;131:256-8.

81. Roussos A, Philippou N, Krietsepi V, et al. Helicobacter pylori seroprevalence in patients with chronic obstructive pulmonary disease. Respir Med. 2005;99:279-84.

82. Pronai L, Schandl L, Orosz Z, Magyar P, Tulassay Z. Lower prevalence of Helicobacter pylori infection in patients with inflammatory bowel disease but not with chronic obstructive pulmonary disease - antibiotic use in the history does not play a significant role. Helicobacter. 2004;9:278-83.

83. Candelli M, Rigante D, Marietti G, et al. Helicobacter pylori eradication rate and glycemic control in young patients with type 1 diabetes. J Pediatr Gastroenterol Nutr. 2004;38:422-5.

84. Lo MK, Lee KF, Chan NN, et al. Effects of gender, Helicobacter pylori and hepatitis B virus serology status on cardiovascular and renal complications in Chinese type 2 diabetic patients with overt nephropathy. Diabetes Obes Metab. 2004;6:223-30.

85. Baricevic I, Nedic O, Nikolic JA, Bojic B, Jojic N. Circulating insulin-like growth factors in patients infected with Helicobacter pylori. Clin Biochem. 2004;37:997-1001.

86. Pearce MS, Steele JG, Campbell DI, Thomas JE. Tooth loss and Helicobacter pylori seropositivity: the Newcastle Thousand Families Cohort Study at age 49-51 years. Helicobacter. 2005;10:90-4. 
87. Albanidou-Farmaki E, Giannoulis L, Markopoulos A, et al. Outcome following treatment for Helicobacter pylori in patients with recurrent aphthous stomatitis. Oral Dis. 2005 Jan;11:22-6.

88. Ahnoux-Zabsonre A, Quaranta M, Mauget-Faysse M. of Helicobacter pylori in central serous chorioretinopathy and diffuse retinal epitheliopathy: a complementary study. J Fr Ophtalmol. 2004;27:1129-33.

89. Miller DM, Espinosa-Heidmann DG, Legra J, et al. The association of prior cytomegalovirus infection with neovascular age-related macular degeneration. Am J Ophthalmol. 2004;138:323-8.

90. Nurgalieva ZZ, Graham DY, Dahlstrom KR, Wei Q, Sturgis EM. A pilot study of Helicobacter pylori infection and risk of laryngopharyngeal cancer. Head Neck. 2005;27:227.

91. Akbayir N, Basak T, Seven H, Sungun A, Erdem L. Investigation of Helicobacter pylori colonization in laryngeal neoplasia. Eur Arch Otorhinolaryngol. 2005;262:170-2.

92. Philippou N, Koursarakos P, Anastasakou E, et al. Helicobacter pylori seroprevalence in patients with lung cancer. World J Gastroenterol. 2004;10:3342-4.

93. Rossi G, Romagnoli S, Lauretti L, et al. Helicobacter pylori infection negatively influences pregnancy outcome in a mouse model. Helicobacter. 2004;9:152-7

94. Abayli B, Colakoglu S, Serin M, et al. Helicobacter pylori in the etiology of cholesterol gallstones. Clin Gastroenterol. 2005;39:134-7.

95. Rocha M, Avenaud P, Menard A, et al. Association of Helicobacter species with hepatitis C cirrhosis with or without hepatocellular carcinoma. Gut. 2005;54:396-401.

96. Huang Y, Fan XG, Wang ZM, et al. Identification of helicobacter species in human liver samples from patients with primary hepatocellular carcinoma. J Clin Pathol. 2004;57:12737. 
97. Sethar GH, Ahmed R, Zuberi BF, Afsar S. Frequency of Helicobacter pylori antibodies in porto-systemic encephalopathy. J Coll Physicians Surg Pak. 2004;14:530-3.

98. O'Rourke JL, Solnick JV, Neilan BA, et al. Description of 'Candidatus Helicobacter heilmannii' based on DNA sequence analysis of 16S rRNA and urease genes. Int J Syst Evol Microbiol 2004;54:2203-11.

99. Shen Z, Xu S, Dewhirst FE, Paster BJ, et al. A novel enterohepatic Helicobacter species 'Helicobacter mastomyrinus' isolated from the liver and intestine of rodents. Helicobacter 2005; 10:59-70.

100. Mikkonen TP, Kärenlampi RI, Hänninen ML. Phylogenetic analysis of gastric and enterohepatic Helicobacter species based on partial HSP60 gene sequences. Int J Syst Evol Microbiol 2004;54:753-8.

101. Hänninen ML, Kärenlampi RI, Koort JM, Mikkonen T, Björkroth KJ. Extension of the species Helicobacter bilis to include the reference strains of Helicobacter sp. flexispira taxa 2, 3 and 8 and Finnish canine and feline flexispira strains. Int $J$ Syst Evol Microbiol 2005;55:891-8.

102. Bourgade F, Montagutelli X, Bigbee C, et al. Simple duplex fecal PCR assay that allows identification of false-negative results in Helicobacter sp.-infected mice. Comp Med 2004;54:528-32.

103. Feng $\mathrm{S}, \mathrm{Ku} \mathrm{K}$, Hodzic E, et al. Differential detection of five mouse-infecting helicobacter species by multiplex PCR. Clin Diagn Lab Immunol 2005;12:531-6.

104. Feng S, Kendall LV, Hodzic E, et al. Recombinant Helicobacter bilis protein P167 for mouse serodiagnosis in a multiplex microbead assay. Clin Diagn Lab Immunol 2004;11:1094-9.

105. Chan V, Crocetti G, Grehan M, et al. Visualization of Helicobacter species within the murine cecal mucosa using specific fluorescence in situ hybridization. Helicobacter 2005;10:114-24. 
106. Young VB, Knox KA, Pratt JS, et al. In vitro and in vivo characterization of Helicobacter hepaticus cytolethal distending toxin mutants. Infect Immun 2004;72:2521-7.

107. Hynes SO, Ferris JA, Szponar B, et al. Comparative chemical and biological characterization of the lipopolysaccharides of gastric and enteric Helicobacters. Helicobacter 2004;9:313-23.

108. Mandell L, Moran AP, Cocchiarella A, et al. Intact gram-negative Helicobacter pylori, Helicobacter felis, and Helicobacter hepaticus bacteria activate innate immunity via toll-like receptor 2 but not toll-like receptor 4. Infect Immun 2004;72:6446-54.

109. Cui G, Koh TJ, Chen D, et al. Overexpression of glycine-extended gastrin inhibits parietal cell loss and atrophy in the mouse stomach. Cancer Res 2004;64:8160-6.

110. Nomura S, Baxter T, Yamaguchi H, et al. Spasmolytic polypeptide expressing metaplasia to preneoplasia in H. felis-infected mice. Gastroenterol 2004;127:582-94.

111. Stoicov C, Whary M, Rogers AB, et al. Coinfection modulates inflammatory responses and clinical outcome of Helicobacter felis and Toxoplasma gondii infections. $J$ Immunol 2004;173:3329-36.

112. O'Rourke JL, Dixon MF, Jack A, Enno A, Lee A. Gastric B-cell mucosa-associated lymphoid tissue (MALT) lymphoma in an animal model of "Helicobacter heilmannii" infection. J Pathol 2004;203:896-903.

113. Rogers AB, Boutin SR, Whary MT, et al. Progression of chronic hepatitis and preneoplasia in Helicobacter hepaticus-infected A/JCr mice. Toxicol Pathol 2004;32:66877.

114. Boutin SR, Rogers AB, Shen Z, et al. Hepatic temporal gene expression profiling in Helicobacter hepaticus-infected A/JCr mice. Toxicol Pathol 2004;32:678-93.

115. Maurer KJ, Ihrig MM, Rogers $\mathrm{AB}$, et al. Identification of cholelithogenic enterohepatic helicobacter species and their role in murine cholesterol gallstone formation. Gastroenterol 2005;128:1023-33. 
116. Myles MH, Livingston RS, Franklin CL. Pathogenicity of Helicobacter rodentium in A/JCr and SCID mice. Comp Med 2004;54:549-57.

117. Livingston RS, Myles MH, Livingston BA, Criley JM, Franklin CL. Sex influence on chronic intestinal inflammation in Helicobacter hepaticus-infected $\mathrm{A} / \mathrm{JCr}$ mice. Comp Med 2004;54:301-8.

118. Pena JA, Rogers AB, Ge Z, et al. Probiotic Lactobacillus spp. diminish Helicobacter hepaticus-induced inflammatory bowel disease in interleukin-10-deficient mice. Infect Immun 2005;73:912-20.

119. Fox JG, Rogers AB, Whary MT, et al. Helicobacter bilis-associated hepatitis in outbred mice. Comp Med 2004;54:571-7.

120. Nilsson H-O, Ouis IS, Stenram U, et al. High prevalence of Helicobacter species detected in laboratory mouse strains by multiplex PCR-denaturing gradient gel electrophoresis and pyrosequencing. J Clin Microbiol 2004;42:3781-8.

121. Goto K, Jiang W, Zheng Q, et al. Epidemiology of Helicobacter infection in wild rodents in the Xinjiang-Uygur autonomous region of China. Curr Microbiol 2004;49:221-3.

122. Van den Bulck K, Baele M, Hermans K, et al. First report on the occurrence of 'Helicobacter heilmannii' in the stomach of rabbits. Vet Res Commun 2005;29:271-9.

123. Park JH, Seok SH, Cho SA, et al. The high prevalence of Helicobacter sp. in porcine pyloric mucosa and its histopathological and molecular characteristics. Vet Microbiol 2004;104:219-25.

124. Terio KA, Munson L, Marker L, Aldridge BM, Solnick JV. Comparison of Helicobacter spp. in cheetahs (Acinonyx jubatus) with and without gastritis. $J$ Clin Microbiol 2005;43:229-34.

125. Oxley AP, Powell M, McKay DB. Species of the family Helicobacteraceae detected in an Australian sea lion (Neophoca cinerea) with chronic gastritis. J Clin Microbiol 
2004;42:3505-12 